\title{
Karakterisasi Bahan Selulosa Dengan Iradiasi Pretreatment Gelombang Mikro Terhadap Serbuk Kayu Cempaka Wasian (Elmerillia Ovalis) Di Sulawesi Utara
}

\author{
Jeafert.R.Pangaua, Hanny.F.Sangiana*, Benny.M.Lumia*, \\ aJurusan Fisika, FMIPA, Unsrat, Manado \\ KATA KUNCI
}

Microvave, pretreatment, cempaka, XRD , SEM, FTIR. \begin{abstract}
A B S TR A K
Kayu cempaka (Elmerrillia ovalis) adalah salah satu jenis tanaman kayu yang dipakai dalam pembuatan rumah adat/rumah panggung dan paling banyak dijumpai di Sulawesi Utara. Industri pembuatan rumah ini menghasilkan limbah kayu dari proses pengergajian. Kayu memiliki komponen kimia utama yaitu selulosa, hemi-selulosa dan lignin yang mana dua komponen pertama dapat dikonversi menjadi gula dan etanol. Modifikasi struktur lignoselulosa yaitu dengan melakukan perlakuan/pretreatment lewat pemanasan dari gelombang mikro (microwave) supaya pemanasan bahan merata/homogen. Keberhasilan modifikasi struktur selulosa dapat dilihat berdasarkan hasil karakterisasi X-RD memperlihatkan bahwa terjadi penurunan kristalinitas ketika dilakukan pretreatment dengan iradiasi gelombang mikro, untuk analisis SEM mengalami perubahan morfologi permukaan struktur, dan untuk analisis gugus fungsi lewat analisis FT-IR yang menunjukkan adanya gerak vibrasi.
\end{abstract}

K E Y W O R D S

Microvave,pretreatment, cempaka, XRD , SEM, FTIR.

\begin{tabular}{l} 
TERSEDIAONLINE \\
\hline 1 Februari 2017 \\
\hline
\end{tabular}

\section{Pendahuluan}

Kecenderungan pemakaian bahan bakar sangat tinggi sedangkan sumber bahan bakar minyak bumi yang dipakai saat ini semakin menipis. Hal ini membutuhkan sumber bahan bakar alternatif lain yang dapat digunakan sebagai pengganti minyak bumi (Ahyar, 2014). Penggunaan etanol dari selulosa sebagai bahan bakar merupakan salah satu upaya pemecahan masalah energi pada saat ini.
Krisis energi diseluruh dunia terutama di Indonesia menyebabkan berbagai upaya menggantikan bahan bakar fosil dengan bahan bakar ramah lingkungan yang dapat diperbaharui (renewable). Bahan yang mengandung selulosa berpotensi digunakan bahan baku bioenergi (Galbe dan Zachli,2007).

Tanaman cempaka (Elmerrillia ovalis) merupakan pohon yang menghasilkan kayu yang banyak tumbuh di Sulawesi Utara. Pohon ini banyak digunakan untuk bahan baku rumah woloan Tomohon Sulawesi Utara yang telah mendapat

*Corresponding author: Jurusan Fisika FMIPA UNSRAT, Jl. Kampus Unsrat, Manado, Indonesia 95115; Email address: hannysangian@yahoo.co.id Published by FMIPA UNSRAT (2017) 
pasar ekspor (Sasmuko, 2010).Kayu dan kulit kayunya mengandung selulosa yang dapat digunakan sebagai bioenergi.

Tanaman cempaka merupakan jenis tanaman tropis yang sangat banyak dijumpai di Indonesia tetapi hasil dari proses industri penggergajian kayu kebanyakan menyisakan limbah padat berupa serbuk gergaji dan serpihan kayu yang terbuang menumpuk di suatu lokasi tertentu yang dapat mengganggu kondisi lingkungan sekitar sehingga diperlukan penanganan terhadap limbah padat hasil penggergajian kayu tersebut (Simbar dkk., 2014).

Kayu cempaka memiliki kandungan serat alam yang terdiri dari selulosa, hemiselulosa dan lignin (Van Vlack, 1994).Selulosa merupakan komponen dasar yang menyusun tumbuhan hidup dan merupakan struktur utama dari dinding sel tumbuhan tingkat tinggi. Selulosa merupakan senyawa organik yang paling melimpah di bumi. Ikatan hidrogen yang berada pada jaringan molekulnya berperan penting dalam menunjukkan sifat-sifat fisik dari selulosa (Balat dkk., 2008).

Salah satu faktor yang perlu diperhatikan dalam memproduksi etanol yaitu efisiensi hidrolisis hemiselulosa dan selulosa menjadi gula monomer/sederhana. Enzim antara lain enzim selulase dapat juga digunakan untuk menghidrolisis selulosa. Namun, pekerjaan enzimatis ini dapat terjadi jika bahan baku selulosa telah diberikan pretreatment terlebih dahulu untuk memodifikasi struktur kristal. Pretreatment ini akan menghilangkan lignin, menurunkan kristalinitas selulosa dan meningkatkan porositas (Galbe dan Zacchi, 2007; Sangian dkk., 2015c; Widjaja dkk.,2015).

Struktur selulosa dapat rusak akibat pemberian pretreatment seperti asam atau basa.Kerusakan selulosa akibat putusnya ikatan hidrogen penyusun serat. Pemberian pretreatmen ionic liquid telah menurunkan kristalinitas selulosa dan meningkatkan aksesibilitas enzim selulase (Hua dkk.,2009; Sangian, 2016). Pretreatment IL terhadap selulosa dari batang gandum juga telah meningkatkan efisiensi hidrolisis enzimatis mikroorganisme khamir Saccharomyces cerevisiae (Li, dkk., 2009). Sangian dkk.(2015b) juga melaporkan bahwa pretreatment IL dalam kondisi basa terhadap tepung batok kelapa juga telah menurunkan kristalinitas selulosa sehingga memudahkan untuk dihidrolisis secara enzimatis.

Pretreatment dengan oven microwave telah dilakukan terhadap bambu (Husnil, 2009) tetapi terhadap kayu cempaka belum pernah dilaporkan.Penelitian ini dilakukan untuk melakukan karakterisasi morfologi struktur selulosa yang terdapat dalam serat kayu cempaka setelah iradiasi pretreatment dengan gelombang mikro (microwave).

\section{Material dan Metode}

Teknik analisis yang dapat digunakan untuk mengetahui struktur molekul (Giancoli, 2001), struktur zat padat kristal (van Vlack, 1994), struktur polimer (Billmeyer, 1984), kristalinitas selulosa (Sangian dkk., 2015a). Sinar X adalah radiasi elektromagnetik yang memiliki panjang gelombang sangat pendek dan energi sangat tinggi (Callister, 2007).Panjang gelombang sinar $X$ berkisar dari $10^{-2}$ $\mathrm{nm}$ hingga $10 \mathrm{~nm}$ (Giancoli, 2001). Foton sinar $X$ dihasilkan ketika elektron yang dari filamen yang dipanaskan mengenai anoda. Anoda akan bertindak sebagai tranduser yang mengubah energi kinetik yang dimiliki elektron menjadi energi panas dan energi radisi elektromagnetik sinar X (Campbel \& Fuller, 1978). Sinar $X$ dihasilkan dalam tabung sinar $X$ sebagaimana tampak pada Gambar 1 di bawah ini.

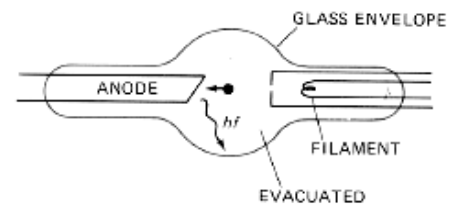

Gambar 1. Tabung sinar X (Campbel \& Fuller, 1978)

Jika elektron mengenai kristal maka sinar $\mathrm{X}$ yang terbentuk akibat tembakan ini akan terhambur ke luar (Surdia, 1993). Sinar X yang merupakan sinar elektromagnetik monokromatik ini akandifraksikan pada sudut teta $\theta$ tertentu.Berkas sinar $\mathrm{X}$ tersebut lalu mengalami interferensi konstruktif pada sudut theta di kedua bidang pada jarak interplanar $d_{\text {hkl }}($ Surdia, 1993; Callister, 2007).Sinar X sangat tepat untuk mempelajari kisi kristal (crystal lattice) disebabkan kristal dapat menyebabkan sinar $\mathrm{X}$ mengalami difraksi (Mortimer, 1993).

Penelitian ini dilakukan atas dua tahap yaitu pertama, preparasi material dan pretreatment dengan microwave dan kedua, pengujian karakterisasi struktur material setelah pretreatment.Tahap pertama dilaksanakan di Laboratorium Intrumentasi dan Energi Terbarukan Jurusan Fisika, FMIPA, Universitas Sam Ratulangi. Tahap kedua pengujian karakterisasi struktur material dengan alat X-RD, SEM dan FT-IR di Laboratorium Sentral Mineral dan Material Maju, FMIPA, Universitas Negeri Malang. Penelitian berlangsung dari bulan Juli2016 sampai Januari 2017

Bahan yang digunakan yaitu serbuk kayu cempaka. Adapun alat-alat yang digunakan pada tahap pertama yaitu microwave, plastik sampel, labu gelas Elenmeyer $250 \mathrm{ml}$, sendok pengaduk, saringan 120 mesh.

Serbuk kayu cempaka ini didapatkan darii limbah pengergajian kayu di Desa Tombatu Satu, Kecamatan Tombatu, Kabupaten Minahasa Tenggara, Provinsi Sulawesi Utara. Serbuk kayu cempaka terlebih dahulu dikeringkan di bawah sinar matahari.Material lalu diayak dengan ayakan berukuran 120 mesh untuk memperoleh ukuran yang sama. Serbuk kayu cempaka yang dipersiapkan sebanyak 20 gram yang akan digunakan sebanyak 10 gram untuk pemaparan dengan gelombang mikro (microwave) dan dengan tanpa pretreatment 
3. Hasil dan Pembahasan

3.1Karakterisasi struktur kristal dengan X-Ray Diffractiom

a. Non-Pretreatment

Hasil karakterisasi struktur kristal dengan X-Ray diffraction menunjukkan puncak tertinggi/total terletak pada intensitas 353 di sudut $2 \theta$ sebesar 22,41 pada intensitas total bidang yang sama dengan Sangian dkk. (2015) yaitu intensitas hkl 002. Puncak lainnya terbaca pada intensitas 221 dan 105 di sudut $2 \theta$ sebesar 15,65 dan 34,75 dengan intensitas bidang hkl masing - masing yaitu 101 dan 040 (Park dkk., 2010). Struktur amorf terdapat di intensitas 135 dengan sudut $2 \theta$ sebesar 18,89. Hasil ini menunjukan bahwa material limbah serbuk kayu cempaka memiliki sifat material kristalin dan non-kristalin.

\section{b. Pretreatment Microwave}

Penelitian dengan pretreatmentmicrowave ini dilakukan untuk mengetahui derajat kristalinitas dan memberikan informasi tentang perubahan struktur mikro yang terjadi pada material limbah serbuk kayu cempaka ketika dilakukan pretreatment menggunakan microwave pada daya (P):300 Watt dalam waktu (T):40 menit.

Hasil karakterisasi X-Ray Diffraction menunjukkan bahwa material limbah serbuk kayu cempaka merupakan suatu bahan material yang bersifat kristal dan non-kristal/amorf dengan puncak-puncak dominan muncul pada daerah sudut $2 \theta$ antara $20^{\circ}-30^{\circ}$. Puncak tertinggi terletak di sudut $2 \theta$ pada titik 21,85 dengan intensitas puncak sebesar 307 dan intensitas total bidang 002 (Sangian dkk., 2015b). Puncak-puncak lain pada posisi $2 \theta$ di titik 15,81 dan 34,07 dengan nilai intensitas masing-masing sebesar 217 dan 94 pada intensitas bidang nilai hkl 101 dan 040 (Park dkk., 2010). Struktur amorf ditemukan pada nilai intensitas 134 pada sudut $2 \theta$ 19,89. Material limbah serbuk kayu cempaka yang diberikan pretreatment microwavesama halnya dengan non preatment memiliki material yang bersifat kristalin dan non-kristalin.

c. Perbandingan X-Ray Diffraction Nonpretreatment dan Pretreatment

Pretreatmentmicrowave material limbah serbuk kayu cempaka yang telah dianalisa dengan pengukuran XRD selanjutnya dibandingkan dengan nilai grafik analisa XRD non - pretreatment. Nilai perubahan kristalinitas yang terjadi pada material limbah serbuk kayu cempaka non-pretreatment dan pretreatmentmicrowave dapat dilihat pada Tabel 1 Rumus Segal digunakan untuk menghitung indeks kristalinitas yaitu:

$$
C r=100 \frac{I_{002}-I_{N o n-c r}}{I_{002}}(\%)
$$

Tabel 1 indeks kristalinitas non - pretreatment dan pretreatment kayu cempaka

\begin{tabular}{|l|l|l|l|l|}
\hline No & Perlakuan & $\begin{array}{l}\text { Inon- } \\
\mathrm{Cr} / \\
\text { IAmorf }\end{array}$ & $\begin{array}{l}\text { Itotal } \\
\text { / I002 }\end{array}$ & $\begin{array}{l}\text { Indeks } \\
\text { Kristalinit } \\
\text { as }\end{array}$ \\
\hline 1. & $\begin{array}{l}\text { Non- } \\
\text { pretreatment }\end{array}$ & 135 & 353 & $61,75 \%$ \\
\hline 2. & $\begin{array}{l}\text { Pretreatment } \\
\text { Microwave }\end{array}$ & 134 & 307 & $56,35 \%$ \\
\hline
\end{tabular}

Material serbuk kayu cempaka merupakan material semi kristal yang tersusun atas material kristal dan non kristal (amorf). Indeks kristalinitas serbuk kayu cempaka sebelum praperlakuan (nonpretreatment) menurun sebesar $8,74 \%$ yang semula $61,75 \%$ menurun menjadi 56,35\% (Tabel 2).

\subsection{Karakterisasi Morfologi Permukaan Scanning Electron Microscopy (SEM)}

Hasil karakterisasi dengan alat scanning electron microscopymenunjukkan ialah foto SEM untuk nonpretreatment material limbah serbuk kayu cempaka, dan foto SEM untuk pretreatment microwave dengan P:300 Watt dan T: 40 menit. Hasil foto SEM menampakkan bahwa telah terjadi perubahan morfologi permukaan serat ketika diberikan pretreatment microwave. Gambar 20 memperlihatkan perubahan struktur morfologi permukaan menjadi porous yang ditunjukkan oleh adanya pori - pori/rongga yang muncul ketika diberikan perlakuan dengan microwave. Ukuran pori - pori membran yang terlihat pada foto SEM digolongkan pada kategori membran konvensional filtrasi disebabkan ukuran pori $10 \mu \mathrm{m}-100 \mu \mathrm{m}$ (Setiawan dkk., 2015).

Hasil foto SEM juga menunjukan permukaan serat pada setiap rongga terlihat kasar dikarenakan lignin berhasil terdegradasi oleh microwave yang diberikan.Hal senada juga disampaikan oleh Dehani-P dkk.(2013) yang menyebutkan permukaan serat jerami padi menjadi tidak kompak, dan menjadi kasar setelah diberikan pretreatment microwave selama 40 menit pada daya 950 watt.Fatriasari dkk. (2016) juga mengatakan yang sama jika pemberian microwave pada daya 330 watt selama 12,5 menit telah menyebabkan perubahan struktur bambu menjadi berlubanglubang dan adanya patahan-patahan.

\subsection{Karakterisasi gugus Fungsi secara} spektrofotometri Fourier Transform Infrared

\section{a. Non-pretreatment kayu cempaka.}

Karakterisasi gugus fungsi dengan FTIR menunjukkan hasil identifikasi gugus fungsi dengan FTIR pada material limbah serbuk kayu cempaka sebelum perlakuan (non-pretreatment).Daerah bilangan di sebelah kanan $1500 \mathrm{~cm}^{-1}$ ialah daerah sidik jari (finger print) (Nomanbhay dkk., 2013).

Pita serapan ulur pada $3467,97 \mathrm{~cm}^{-1}$ dan $3272,93 \mathrm{~cm}^{-1}$ menunjukkan adanya gugus hidroksil (O-H) dari selulosa sebagaimana dilaporkan juga oleh berbagai peneliti (Sukadana, 2010; Ciolacu dkk., 2011; Kumar dkk., 2014; Fatriasari dkk., 2016) 
Setelah itu, serapan yang terbaca berikutnya pada bilangan gelombang 2910,31 cm-1 yang merupakan serapan ulur dari gugus $\mathrm{C}-\mathrm{H}$. Gugus fungsional $\mathrm{C}-\mathrm{H}$ ialah kerangka selulosa tampak pada bilangan gelombang 2800 - $3000 \mathrm{~cm}^{-1}$ (Kinney dkk., 2012). Gugus ini terletak di sebelah kanan gugus $\mathrm{O}-\mathrm{H}$. Area peregangan ikatan $\mathrm{C}-\mathrm{H}$ pada tebu juga dilaporkan pada gelombang 2850-2970 cm 1 (Kumar dkk., 2014) dan $2900 \mathrm{~cm}^{-1}$ (Ciolacu dkk., 2011).

Bilangan gelombang $2141 \mathrm{~cm}^{-1}$ menunjukkan gugus fungsi $\mathrm{C} \equiv \mathrm{C}$ dari senyawa hidrokarbon. Serapan gugus $\mathrm{C} \equiv \mathrm{C}$ akan tampak pada bilangan gelombang $2140 \mathrm{~cm}^{-1}-2260 \mathrm{~cm}^{-1}$ (Day \& Underwood, 2001).

Serapan gugus karbonil $\mathrm{C}=0$ yang menunjukkan kehadiran hemiselulosa terbaca pada bilangan gelombang $1742,53 \mathrm{~cm}^{-1}$. Area vibrasi ulur gugus $\mathrm{C}=0$ tampak pada serapan $1724 \mathrm{~cm}^{-1}$ (Fan dkk., 2012), $1700 \mathrm{~cm}^{-1}$ (Kinney dkk., 2012), $1730 \mathrm{~cm}^{-1}$ untuk ikatan asetil dan ester yang terdapat dalam lignin, hemiselolosa dan pektin (Kumar dkk., 2014).

Area vibrasi uluran sekitar $1650 \mathrm{~cm}^{-1}$ menunjukkan ikatan $\mathrm{O}-\mathrm{H}$ yang menyerap air.Bilangan gelombang $1620-1649 \mathrm{~cm}$-1 oleh Kumar dkk (2014).Struktur lignin terbaca pada bilangan gelombang 1648 dan $1583,56 \mathrm{~cm}^{-1}$ (Fatriasari dkk., 2016). Ini menunjukkan kehadiran lignin pada serbuk kayu cempaka.

Selulosa terdiri atas unit - unit glukosa.Bentuk dari glukosa ini tidak mutlak pada saat keadaan siklik dan glukosa juga dapat stabil ketika bentuk rantai glukosa terbuka pada saat proyeksi Fisher. Hal ini dapat diperkuat dengan adanya serapan ulur dari gugus aromatik simetri $\mathrm{C}=\mathrm{C}$ pada bilangan gelombang 1583,56 cm-1; 1503,65 cm-1; 1467,56 $\mathrm{cm}^{-1}$ dan $1506 \mathrm{~cm}^{-1}$ (Kinney dkk., 2012).

Pita spektral pada $1421,54 \mathrm{~cm}^{-1}$ menunjukkan vibrasi $\mathrm{CH}_{2}$. Serapan $1423 \mathrm{~cm}^{-1}$ telah digunakan Fan dkk.(2012) untuk identifikasi gugus $\mathrm{CH}^{2}$. Area bilangan gelombang $1420-1430 \mathrm{~cm}^{-1}$ disebut juga sebagai pita kristalinitas (Ciolacu dkk., 2011; Kumar dkk., 2014).

Serapan tekuk gugus $\mathrm{C}-\mathrm{H}$ tampak pada bilangan gelombang $1327 \mathrm{~cm}^{-1}$ dan $1369 \mathrm{~cm}^{-1}$. Nomanbhay dkk. (2013) melaporkan bahwa gugus $\mathrm{C}-\mathrm{H}$ ditemukan pada bilangan gelombang $1316 \mathrm{~cm}^{-1}$ untuk senyawa dari senyawa selulosa dan $1372 \mathrm{~cm}^{-}$ ${ }^{1}$ dari senyawa selulosa dan hemiselulosa.

Serapan bilangan gelombang $1232,51 \mathrm{~cm}^{-1}$ menunjukkan kehadiran gugus fungsi $\mathrm{C}=$ dari lignin dan xilan/hemiselulosa. Kehadiran gugus $\mathrm{C}=$ ini tampak pada bilangan gelombang $1235 \mathrm{~cm}^{-1}$ dari serat TKKS (Nomanbhay dkk., 2013)

Bilangan gelombang 1159,22-1033,85 cm-1 merupakan area vibrasi C-O-C. Fan dkk. (2012) menemukan gugus C-O-C pada vibrasi $895 \mathrm{~cm}^{-1}$, $1152 \mathrm{~cm}^{-1}$ dan $1204 \mathrm{~cm}^{-1}$.Gugus C-O-C merupakan struktur dari lignin yang menjadi penyusun kayu. Serapan gugus C-H aromatik tampak pada 1033,85 $\mathrm{cm}^{-1}$. Gugus $\mathrm{C}-\mathrm{H}$ aromatik menurut Nomanbhay dkk.(2013) juga ditemukan pada 1034 cm
1.Kehadiran gugus C- $\mathrm{H}$ aromatik menunjukkan kehadiran lignin (Fatriasari \& Hermiati, 2016).

Area penyerapan ikatan selulosa $\beta$-glycosidic tampak pada bilangan gelombang $829,10 \mathrm{~cm}^{-1}$ dan $902,14 \mathrm{~cm}^{-1}$. Serapan ikatan ini akan tampak pada bilangan gelombang 950- $800 \mathrm{~cm}^{-1}$ (Kumar dkk., 2014) atau $897 \mathrm{~cm}^{-1}$ (Nomanbhay dkk., 2013). Pita spektral $898 \mathrm{~cm}^{-1}$ disebut juga pita penyerapan amorf (Ciolacu dkk., 2011). Serapan 670,13 cm-1 menunjukkan serapan gugus fungsi $\mathrm{C}-\mathrm{H}$ cincin aromatik dari lignin (Fatriasari \& Hermiati, 2016).

\section{b.FTIR Pretreatment microwave.}

Hasil grafik spektrum FTIR limbah serbuk kayu cempaka ketika diberikan pretreatmentmicrowave tampak pada Gambar 22. Berdasarkan nilai serapan spektrum inframerah yang didapatkan dari hasil penelitian ini, dapat dilihat bahwa senyawa yang didapatkan menunjukan serapan melebar dan lemah pada daerah bilangan gelombang 3493,61 $\mathrm{cm}^{-1}$ yang merupakan serapan ulur dari gugus $\mathrm{O}-\mathrm{H}$ (Silverstein dkk., 1991). Serapan yang terbaca berikutnya yaitu 2902,55 $\mathrm{cm}^{-1}$ yang merupakan serapan ulur gugus C-H (Creswell, 2012).

Serapan ulur pada gugus $\mathrm{C}=\mathrm{C}$ terbaca pada daerah bilangan gelombang 1460,06 cm-1; 1503,19 $\mathrm{cm}^{-1}$; dan 1583,86 $\mathrm{cm}^{-1}$ (Lionetto dkk., 2012). Gugus cincin aromatik $\mathrm{C}=\mathrm{C}$ tampak pada 1500 $1600 \mathrm{~cm}^{-1}$ (Sopiah dkk., 2015).

Serapan tekuk gugus $\mathrm{C}-\mathrm{H}$ tampak pada bilangan gelombang $1328,27 \mathrm{~cm}^{-1}$ yang menunjukkan kehadiran senyawa selulosa. Serapan bilangan gelombang $1234,02 \mathrm{~cm}^{-1}$ menunjukkan adanya gugus fungsi $\mathrm{C}=$ dari lignin dan hemiselulosa (Nomanbhay dkk., 2013).

Area serapan C-O-C dari lignin tampak pada bilangan gelombang $1260,54 \mathrm{~cm}^{-1}, 1124,60 \mathrm{~cm}^{-1}$ dan 1031,30 cm-1 (Fan dkk., 2012). Bilangan gelombang $1033,85 \mathrm{~cm}^{-1}$ yang diduga gugus $\mathrm{C}-\mathrm{H}$ aromatik dari lignin juga masih tampak (Fatriasari \& Hermiati, 2016).

Area penyerapan ikatan selulosa $\beta$-glycosidic tampak pada bilangan gelombang $829,10 \mathrm{~cm}^{-1}$ dan $902,14 \mathrm{~cm}^{-1}$. Serapan ikatan ini akan tampak pada bilangan gelombang 950- $800 \mathrm{~cm}^{-1}$ (Kumar dkk., 2014) atau $897 \mathrm{~cm}^{-1}$ (Nomanbhay dkk., 2013). Pita spektral $898 \mathrm{~cm}^{-1}$ disebut juga pita penyerapan amorf (Ciolacu dkk., 2011). Serapan gugus C-H aromatik terbaca pada daerah bilangan gelombang $695,39 \mathrm{~cm}-1 ; 856,23 \mathrm{~cm}-1$ dan 897,12 cm-1 (Silverstein dkk., 1991).

\section{Kesimpulan}

Pretreatment dengan gelombang mikro (microwave) kepada serbuk kayu cempaka (Elmerillia ovalis) pada daya (P) 300 watt dan suhu (T) 40 menit telah menyebabkan perubahan karakterisasi sifat fisik serbuk kayu cempaka.

Hasil karakterisasi dengan X-Ray Diffraction memperlihatkan telah terjadi penurunan kristalinitas dari $61,75 \%$ (non pretreatment) menjadi 56,35\% (pretreatment). Struktur kristal pada puncak tertinggi pada intensitas 353 di sudut 
$2 \theta$ pada titik 22,41 dan struktur non-cristal (amorf) pada intensitas 135 di sudut $2 \theta$ pada titik 18,89 untuk non-pretreatment. Penurunan struktur kristal pada intensitas sebesar 307 di sudut $2 \theta$ pada titik 21,85 dan struktur non-cristal pada intensitas 134 pada sudut $2 \theta 19,89$ untuk pretreatment.

Analisis karakterisasi berdasarkan SEM menunjukkan bahwa iradiasi gelombang mikro telah menyebabkan perubahan morfologi permukaan serbuk kayu cempaka. Permukaan serbuk kayu berhasil bertransformasi menjadi lebih berongga dan bertekstur setelah dilakukan pretreatment dengan microwave.

Analisis spektra FT-IR menunjukkan bahwa pretreatment microwave belum memperlihatkan perubahan gugus-gugus fungsional dibandingkan dengan non pretreatment. Kesamaan gugus-gugus fungsi tampak pada serapan lebar $3200-3500 \mathrm{~cm}^{-1}$ (OH) pada selulosa, 2900-2910 $\mathrm{cm}^{-1}(\mathrm{CH})$, sekitar $1700 \mathrm{~cm}^{-1}(\mathrm{C}=0), 1365-1370 \mathrm{~cm}^{-1}(\mathrm{C}-\mathrm{H}$ selulosa dan hemiselulosa), 1124-1260 $\mathrm{cm}^{-1}$ (C-O-C), 829-902 $\mathrm{cm}^{-1}$ (B-glycosidic) dan 670-695 $\mathrm{cm}^{-1}$ (C-H cincin aromatik).

\section{Daftar Pustaka}

Ahyar, A. 2014. Bioethanol Production from cellulose in red algae Gracilaria verrucosa by separated hydrolysis and fermentation system using trichoderma viride and zymomonaz mobilis. International Journal of Phasrma and Bio Sciences.5(2):445- 452.

Balat, M., H. Balat dan C. Oz. 2009.Progress in bioethanol Combust. Sci. 34 (5):551-573.

Billmeyer, F.W.1996. Textbook of Polymer Science.Edisi ke-3. New York: John Wiley and Sons.

Callister, W.D. 2007.Materials Science and Engineering: An Introduction. John Wiley \& Sons, Inc. New York.

Campbel,T. C.\& R.G.Fuller. 1978. Study Guide to accompany Physics Including Human Applications. New York: Harper \& Row, Publishers.

Creswell, C.J. et al. 2005. Analisa Spektrum Senyawa Organik. Cetakan ke-10.Edisi ketiga.Penerjemah Kosasih Padmawinata dan Iwang Soediro.Penerbit ITB. Halaman :1-100. Bandung.

Day, R.A. \& A.L. Underwood. 2001. Analisis Kimia Kuantitatif. Terjemahan I.Sopyan. Edisi ke-5. Jakarta: Penerbit Erlangga.

Fan, M., D. Dai \& B. Huang. 2012. Fourier Transform Infrared Spectroscopy for Natural Fibres.In Fourier Transform - Materials Analysis. Salih Salih (Ed.). Intech. http://www.intechopen.com/books/fouriertransform-materials-analysis/fourier-transforminfraredspectroscopy-for-natural-fibres.45-68 pp. [3 Februari 2017].
Fatriasari, W., W.Syafii, N. Wistara, K.Syamsul dan B.Prasetya. 2016. Lignin and cellulose changes of betung bamboo (Dendrocalamus asper) pretreated microwave heating. International Journal on Advanced Science Engineering Information Technology.6(2): 186-195.

Fatriasari, W \& E. Hermiati. 2016. Lignocellulosic biomass for bioproduct: its potency and technology development: A Review. J. Lignocellulose Technol. 1:1-14.

Galbe, M dan G. Zachii. 2007. Pre-treatment of Lignocellulosic Materials forEfficient Bioethanol Production. Biofuels.Advancesin Biochemical Engineering/Biotechnology 108:41-65.

Giancoli, D.C. 2001. Fisika.Jilid 2.Edisi ke-5. Jakarta. Penerbit Perlangga.

Hua, Z. L. Cecil, G. Jones, A. Baker, X. Shuqian, O. Olarongbe dan V.N. Person. 2009. Regenerating cellulose from ionic liquids for an accelerated enzymatic hydrolysis. Journal of Biotechnology139: 47-54.

Husnil, Y.A. 2009.Perlakuan Gelombang Mikro dan Hidrolis Enzimatik pada Bambu untuk Pembuatan Bioetanol.[Tesis]. Universitas Indonesia.Depok

Kinney, T.J., C.A. Masiello, B. Dugan, W.C. Hockaday, M.R. Dean, K. Zygourakis dan R.T. Barnes. 2012. Hydrologic properties of biochars produced at different temperatures. Biomass and Bioenergy.30: 1-10.

Kumar, A., Y. S. Negi, V.Choudhary \& N. K.Bhardwaj. 2014. Characterization of Cellulose Nanocrystals Produced by Acid-Hydrolysis from Sugarcane Bagasse as Agro-Waste .Journal of Materials Physics and Chemistry.2 (1): 1-8.

Li, Q., Y-C.He, M. Xian, G.Jun, X. Xu, J-M. Yang, dan L-Z. Li. 2009.Improving enzymatic hydrolysis of wheat straw using ionic liquid 1-ethyl methylimidazolium diethyl phosphate pretreatment. Bioresource Technology100:3570-3575.

Lionetto, F. R.D. Sole, Cannoletta, D. Vasapollo, G. Maffezzoli, A. 2012. Monitoring Wood Degradation during Weathering by Cellulose Crystallinity.Materials 5:1910-1922.

Mortimer, R.G. 1993. Physical Chemistry. Redwood City: The Benjamin/Cummings Publishing Company, Inc.

Nomanbhay, S.M., R. Hussain \& K.Palanisamy. 2013. Microwave-Assisted alkaline pretreatment and microwave assisted enzymatic saccharification of oil palm empty fruit bunch fiber for enhanced fermentable sugar yield. Journal of Sustainable Bioenergy Systems.3: 7-17.

Park, S. Baker, J.O. Himmel, M.E. Parilla, P.A. Johnson,D.K. 2010. Cellulose Crystallinity Index: Measurement Techniques and Their Impact onInterpreting Cellulose Performance. Biotechnology for Biofuels. 10.1186/17546834-3-10 
Sangian, H.F., J. Kristian, S.Rahma, H.K.Dewi, D.A..Puspasari, S.Y.Agnesty, S.Gunawan dan A. Widjaja. 2015a. Preparation of reducing sugar hydrolyzed from high-lignin coconut coir dust pretreated by the recycled ionic liquid [mmim][dmp] and combination with alkaline.Bulletin of Chemical Reaction Engineering \& Catalysis.10 (1): 8-22.

Sangian, H.F., J. Kristian, S.Rahma, S.Y.Agnesty, S.Gunawan dan A. Widjaja. 2015b. Comparative Study of the Preparation of Reducing Sugars Hydrolyzed from HighLignin Lignocellulose Pretreated with Ionic Liquid, Alkaline Solution and Their Combination. J. Eng. Technol. Sci.47 (2): 137148

Sangian, H.F., D. Ranggina., G.M.Ginting., AA. Purba.,S. Gunawan., A. Widjaya. 2015c. Study of the Preparation of Sugar from High-Lignin Lignocellulose Applying Subcritical Water and Enzymatic Hydrolysis: Synthesis and Consumable Cost Evaluation. Scientific study\& Research Chemistry \& Chemical Engineering, Biotechnology, Food Industry. 16(1):013-027.

Sangian, H.F. 2016. Analysis of retention time and substances released enzymatically fromlignocellulose, coconut coir treated by alkaline, ionic liquid [mmim][dmp] and combined method by observing the HPLC-RI spectra. International Journal of ChemTech Research.9(12):715-724.
Sasmuko S.2010. Wood properties of local species for wooden house of woloan in north Celebes Province.

Setiawan, D.A., Argo, B.D., Hendrawan, Y., 2015. Pengaruh konsentrasi dan preparasi membran terhadap karakterisasi membran kitosan. Jurnal keteknikan pertanian tropis dan biosistem.3:(1) : 95-99

Simbar M, M Theodora. Katiandagho, Lolowang T.F., Baroleh J. 2014. Analisis Pengendalian Persediaan Bahan Baku Cempaka pada Industri Mebel dengan menggunakan metode EOQ (Studi Kasus pada UD Batu Zaman). Cocos 5(3)

Silverstein, R. M., Bassler, G.C., \& Morril, T.C., 1991, Spectrometric Identification of Organic Coumpounds (Vol.Ed.5). Jhon Wiley \&Sons,Inc., New york.

Sukadana, Imade. 2010. Aktifitas Senyawa Flafonoid Dari Kulit Akar Awar-awar.4 (1):63-67.

SurdiaN.M. 1993. Ikatan dan Struktur Molekul.Jakarta.

Van Vlack, LH. 1994. Ilmu dan Teknologi Bahan: IImu Logam dan Bukan logam.Terjemahan S.Djaprie. Edisi ke-5. Jakarta: Penerbit Erlangga.

Widjaja, A., S.Y.Agnesty., H.F.Sangian., dan S.Gunawan dan 2015. Application of Ionic Liquid [DMIM] DMP Pretreatment in the Hydrolysis of sugarcane Bagase for Biofuel Production.Buletin of Chemical Reaction Engineering \& Catalysis.10(1);70-77. 